

Emma Bergström

Leg. Psykolog

Linnéuniversitetet

emma.bergstrom@Inu.se

Sara Wijk

Verksamhetsutvecklare, projektledare Språkstegen

Biblioteksutveckling Blekinge Kronoberg

sara.wijk@regionblekinge.se

\title{
Tidig språkintervention med dialogläsning - forskning och praktik
}

Följande paper är skrivet utifrån två olika perspektiv; det teoretiska och det pragmatiska. Texten vill förmedla hur delar av den omfattande kunskap som finns rörande barns språkutveckling kan omsättas i konkreta insatser för små barn och deras föräldrar. Genom att förmedla kunskap både från det teoretiska och det praktiska perspektivet hoppas författarna erbjuda nya perspektiv och kunskaper kring ett gemensamt objekt.

Ur ett samhällsperspektiv är det av största vikt att alla barn får tillgång till ett rikt språk och föräldrarna spelar en avgörande roll för barns språkutveckling. I en klassisk långtidsstudie av Hart \& Risley (1995) fann forskarna att de barn som växte upp i en rik språklig miljö tillägnade sig ett större ordförråd jämfört med barn som växte upp i en torftig språklig miljö. Studien följde barnen i deras naturliga hemmiljö från de var nio månader till barnen fyllde tre år. I en uppföljande studie, när barnen var åtta till nio år, visade resultaten att klyftan mellan grupperna kvarstod (Walker et al 1994).

Studier har visat att små barn som blir lästa för under förskoleåldern har lättare att tillägna sig ett språk och utvecklar ett större ordförråd vilket underlättar läs- och skrivinlärningsprocessen (Mol \& Bus 2011, Bus, IJzendoorn \& Pellegrini 1995, Zevenbergen \& 
Whitehurst 2003, Dickinson et al 2012, Lyytinen et al 1998). Små barn med ett rikt ordförråd och god språkutveckling har goda förutsättningar för läsningens olika komponenter: avkodning, läsförståelse och läshastighet (Bartl-Pokorny et al 2013). En tidig debut av högläsning i hemmet påverkar även andra skolämnen positivt, exempelvis matematik (Shahaeian et al 2018). Den naturliga följden av denna kunskap är att föräldrar behöver informeras om vikten av att interagera språkligt, på många olika sätt, tillsammans med sitt barn och att det är bra att börja tidigt i barnets liv.

\section{Tidig lässtimulans i hemmet - Bokstart och andra satsningar}

2015 initierade Statens Kulturråd med inspiration från bl a England och Danmark tre pilotprojekt i Sverige för att främja tidig litteracitet genom föräldrastöd (Kulturrådet s.7). Dessa skulle snart följas av ytterligare två. Kulturrådet fick senare i uppdrag att bredda Bokstart till ett nationellt stödprogram. Som i övriga länder gick projektet och programmet under namnet Bokstart. Även Region Hallands olika projekt som till viss del föregick Bokstart bör nämnas. Dessa har på ett särskilt sätt bidragit till kunskapsuppbyggnaden i den svenska kontexten. Med stöd av Kulturrådet har en kunskapsöversikt, enkätstudie samt dokumentation och utvärdering av de halländska projekten, samt förslag till utvecklat arbete lagt en viktig grund för allt fortsatt arbete (Rydsjö 2012). Därutöver har flera regionala och lokal projekt med lite olika betoning funnits. Till exempel var region Uppsala tidiga att hitta strukturer och teoribildning för samverkan. Inte minst genom att vidareutveckla Öglands taxonomi (Ögland 2013) för att skapa ramar och överenskommelser för samverkan i s k språknätverk (Region Uppsala 2018). På nära håll, i Markaryd, pågick under många år Boknallen (Svensson 1989). Nycklarna till framgång i alla projekten har varit professionsöverskridande samarbeten och ett riktat stöd till föräldrar.

\section{Språkstegen}

Sneglande på ovan nämnda projekt började barnhälsovård, regionbibliotek, folkbibliotek och representanter för logopedi i Blekinge och Kronoberg vårterminen 2016 att tillsammans skissa på ett eget koncept som senare skulle kallas Språkstegen. Tidigare hade det inte funnits något regionalt samarbete kring frågorna. Folkhälsopolitikerna i Kronoberg hade däremot genom ett måldokument (Region Kronoberg 2014) i ett av målen pekat ut just samverkan för de yngsta barnen mellan några av nämnda huvudmän samt förskolan som en länsgemensam åtgärd. Samverkan i Språkstegen sker kring barnet och familjens bästa. Det är av vikt att för detta syfte tillsammans ta tillvara kunskap, erfarenhet och praktiska förutsättningar.

Barnhälsovården arbetar vid alla kontakttillfällen under barnets uppväxt, 0-6 år, med dialog och hälsofrämjande möten för att göra skillnad, skapa förståelse för och förmedla kunskap om språk, kontakt och kommunikation bland flera andra fokusområden. Vid vissa besök läggs särskild tonvikt på språkutveckling, samtal om läsning och information om bibliotek. Detta sker genom att främja lyhört föräldraskap, främja barnets utveckling, kompetens och delaktighet (Rikshandboken Barnhälsovård 2018). Barnhälsovården i Sverige har ett stort förtroende och når de flesta av landets småbarnsfamiljer med det nationella programmet (Wallby 2012).

Folkbiblioteken har i Bibliotekslagens $8 \S$ ett tydligt uppdrag att "ägna särskild uppmärksamhet åt barn och ungdomar för att främja deras språkutveckling och stimulera till 
läsning" (SFS 2013:801) och har en lång tradition att samverka med barnhälsovård. Detta är dock sällan reglerat i styrdokument, särskilt systematiskt utfört eller utvärderat (Rydsjö 2012). Biblioteket har kunskap om läsning som praktik, erbjuder en barnvänlig tillgänglig plats för alla med böcker för varje unika barns behov.

Logopedernas professionella objekt är språk, tal, röst och kommunikation. Trots att de till vardags ofta till liten del arbetar strategiskt eller preventivt är det av mycket stor vikt att ha med deras djupa kunskap och expertis för att kvalitetssäkra dessa delar i arbetet med föräldrastöd kring tidigt läsfrämjande.

Ett tidigt val var att göra begränsade insatser men i bredd. Alla barn i alla tretton kommuner skulle inkluderas, vilket skulle innebära att knappt 4000 barn per årskull, skulle ingå. I första hand ville man prioritera kunskapsöverföring, individanpassning och ett coachande arbetssätt i alla led framför ett större antal bokgåvor. Arbetsgruppen med representanter från alla sektorerna valde också att använda befintliga strukturer och arbeta evidensbaserat, långsiktigt, jämlikt, med god förankring och i möjligaste mån inom befintliga ramar.

De insatser som planerades i Språkstegen var:

- Alla barn får boken Knacka på av Anna-Clara Tidholm vid 8 månader av barnhälsovården vid hembesök. Introduktion och tillämpning av dialogläsning med barnet, information, motivation och riktad inbjudan till det lokala biblioteket.

- Bibliotekspersonal och BHV-sjuksköterska medverkar tillsammans i alla föräldragrupper vid ett särskilt tillfälle om språkutveckling, läsning, böcker och bibliotek.

- Bibliotek i alla kommuner erbjuder öppna program för 0-3 år med ett lågt insteg så att det alltid finns språkstimulerande aktiviteter att bjuda in till.

- Alla barn får vid 18-månadersbesöket på BVC ett individanpassat samtal kring läsning och språkutveckling. Dialogläsning med barnet och presentkort på samma bok delas ut. Boken är en gåva från biblioteket där den hämtas.

- Lokal samverkan mellan professioner i lokala Språkstegennätverk i varje kommun.

- BHV och Bibliotek arbetar tillsammans med läsfrämjande väntrum på BVC.

- Regelbunden utbildning för personal som arbetar med Språkstegen. (Språkstegen 2018) 


\section{Samspel, språkutveckling och högläsning - teoretiskt underlag för Språkstegen}

Relationen mellan barnet och dess förälder utvecklas över tid. I den tidiga kontakten behöver föräldern uppfatta och lära sig tolka barnets kommunikation. Att som förälder se och förstå bebisens signaler är till en början svårt. Allt eftersom föräldrar och barn lär känna varandra utvecklar föräldern förståelse för barnets unika "språk". Förälderns förmåga att sätta sig in i barnets inre upplevelser, förstå barnets specifika behov och vad barnet förmedlar är en viktig ingrediens i relationsutvecklingen mellan dem. Den förälder som är lyhörd, lär sig förstå sitt barns kommunikation och svarar på barnets behov skapar förutsättningar som påverkar barnets utveckling positivt. (Broberg 2017, Karlsson 2012). Detta är en mycket förenklad beskrivning av hur relationen mellan förälder och barn utvecklas över tid.

Barnets icke-verbala kommunikation utvecklas till ett rikt och nyanserat språk och är en komplex process. Före det verbala språkets utveckling tränar spädbarnet på och använder sig av annan kommunikation för att på olika sätt förmedla sina behov. Detta sker med hjälp av kroppsspråk, ögonkontakt, ansiktsmimik och olika typer av ljud. Talets utveckling grundas i barnets joller, utvecklas via ettordsmeningar för att inom några få år bestå av komplexa meningar (von Tetzchner 2016, Westerlund 2009). Enligt Vygotskij är det i samspelet med en vuxen, som anpassar sig efter barnets utvecklingsnivå, som barnets språkutveckling sker (von Tetzchner 2016). Dickinson et al (2012) förklarar i sin forskningsöversikt att följande faktorer gynnar barns språkinlärning: (a) barn behöver höra många ord och höra dem ofta, (b) barn lär sig ord när de är intresserade, (c) barn lär sig bäst när vuxna ger dem uppmärksamhet, (d) barn lär sig ord när de förstår ordens betydelse, (e) ord och grammatik tillsammans erbjuder barnet bra grund för inlärning och slutligen ( $f$ ) en positiv och uppmuntrande miljö främjar språkutveckling. Dessa faktorer kan implementeras genom att föräldern som läser högt med sitt barn.

Som nämnts tidigare gynnas små barns språkutveckling av att vuxna skapar en språkligt rik miljö kring dem och detta kan med fördel ske genom högläsning (Dickinson et al 2012, Isbell et al 2004, DeBaryshe 1993). Att små barns språkutveckling påverkas positivt genom högläsning är väl beforskat (Bus \& van IJzendoorn 1995, Fletcher \& Reese 2005, Mol et al 2008, Isbell et al 2004). Barnboken erbjuder flera fördelaktiga beståndsdelar. Exempelvis kan texten i boken exponera barnet för miljöer och vokabulär utanför dess egna välbekanta hemmiljö (Montag et al 2015, De Temple \& Snow 2003, Dickinson et al 2012). Texten i barnboken erbjuder ett mer sofistikerat språk (Montag et al 2015) jämfört med det språk som förekommer i vardagliga samtal och tv-program (Duursma et al 2008).

Barnboksskaparen har övervägt ordval, formuleringar, meningar och representation av ord $\mathrm{i}$ bildberättande för att orden i boken skall presenteras vid upprepade tillfällen och i olika grammatiska former, något som underlättar för barnet när det bekantar sig med nya okända ord. Föräldrar använder sig ofta av boken som ett instrument att lära ut nya ord då de oftare benämner objekt under högläsning jämfört med exempelvis under samtal eller lek (Montag et al 2015, Duursma et al 2008). Illustrationerna i barnböcker hjälper barnet att behålla fokus, underlättar förståelse av berättelsen och erbjuder bilder på objekt som tilltalar barnet. En uppmärksam vuxen kan med fördel se barnets riktade intresse för en bild och följsamt utveckla berättelsen kring objektet (Dickinson et al 2012). 
Många forskarlag har studerat föräldrafaktorer och omständigheter i barnens hemmiljö för att förstå vad som påverkar föräldrars beslut att börja läsa för sina barn, vad som påverkar frekvensen av läsning och vilka faktorer som eventuellt hindrar läsning i vardagen.

DeBaryshe (1993) fann att barn vars föräldrar började läsa tidigt i barnets liv hade ett mer välutvecklat språk vid två års ålder. Karrass et al (2003) fann att välutbildade föräldrar med hög inkomst läste för sina barn från tidigare ålder jämfört med föräldrar som tillhörde andra samhällsklasser. Förutom mödrarnas utbildningsnivå, fann Lyttinen et al (1998) att moderns eget läsintresse korrelerar med barnens språkutveckling vid 2 års ålder. Ekonomisk stabilitet, barnets temperament, barnets kön och koncentrationsförmåga är andra faktorer som påverkade föräldrarnas läsdebut för sina barn (Karrass et al 2003). Barnets eget intresse av lässtunden har även visat sig påverka hur ofta barnet blir läst för. Barn som har god språkutveckling vid 14 månader visar mer intresse för och initierar oftare förälders läsning jämfört med barn som inte har ett lika välutvecklat språk. Dessa barn visar även på ökad uthållighet i lässtunden (Lyytinen et al 1998). Stress i vardagen, stora påfrestande livshändelser, föräldrarnas psykiska mående, lågt socialt stöd och storlek på familjen var faktorer som påverkade förälderns läsdebut och frekvens negativt (Zevenbergen \& Whitehurst 2003).

Som tidigare nämnts är kvalitén på föräldra-barnrelationen viktig med hänsyn till barnets utveckling. Forskning har visat att relationskvalitén även påverkar lässtunden. De barn som utvecklat en trygg anknytning till sina mödrar erhöll en rikare och mer interaktiv högläsningsstund. Dessa mödrar uppmuntrade till mer läsning och var mindre tillrättavisande i lässtunden, något som gynnade barnets språkinlärning (Bus \& van IJzendoorn 1988, Bus \& van IJzendoorn 1995).

Förälderns förmåga att engagera och uppmuntra barnet i lässtunden genom att ställa frågor och be barnet att identifiera objekt ökar barnets möjlighet att utveckla sitt språk mer jämfört med barn som har en mer passiv och lyssnande roll (Dickinson et al 2012). En sådan metod som strävar efter att höja barnets förmåga att aktivt delta i läsningen kallas dialogläsning.

\section{Dialogläsning som metod}

Zevenbergen \& Whitehurst (2003) fann att barns språkutveckling påverkas positivt om föräldrarna engagerar barnen i lässtunden genom att ställa frågor som uppmuntrar barnen att delta i "berättandet". Frågorna utformades utifrån barnets ålder och mognad. Barnen fick svara på frågor som uppmuntrade deras verbala engagemang. Allt eftersom barnets språk utvecklades ställdes frågor som uppmuntrade till mer avancerat tal. Studier visade att barn som blir lästa tillsammans med genom denna metod, så kallad dialogläsning, utvecklar sitt språk mer än de barn som har en mer traditionell, passiv, lyssnande roll under högläsningsstunden.

I litteraturen härleds dialogläsning till Whitehurst och hans forskarkollegor (1988). Forskarnas ambition var att designa en studie för att tydligt visa läsningens effekter på språkutveckling hos barn. Författarna utvecklade en metod där den vuxne använder olika uppmuntrande tekniker för att främja barnets verbala medverkan. 
Dessa tekniker beskrivs enligt följande (Whitehurst et al 1988):

1) Den vuxne uppmuntrar till och fokuserar lässtunden efter barnets intresse.

2) Den vuxne pekar och benämner saker/händelser/känslor som barnet visar intresse för.

3) Den vuxne förstärker objektet som barnet visar intresse för genom att animera/betona dessa under lässtunden.

4) Den vuxne använder "Var är...." frågor. (hittar du, kan du visa mig)

5) Den vuxne använder "Vad eller vem" frågor. "Vad är det här?" (peka på ett objekt).

6) Innehållet kopplas till barnets egen värld/erfarenheter. Barnets mognad/förståelse styr hur abstrakt kopplingen blir.

Zevenbergen \& Whitehurst (2003) beskriver att dialogläsningens mål är att uppmuntra barnet att över tid bli den som återger berättelsen. Den vuxnes uppgift är att ställa lämpliga frågor utifrån barnets mognad och ålder, utveckla barnets verbala bidrag, ge beröm för barnets försök att berätta, benämna objekt och slutligen bör den vuxne utmana barnet genom att föra samtal och ställa frågor som kräver att barnets svar ligger på en mer avancerad språklig nivå (De Temple \& Snow, 2003). Dialogläsning, då den uppmuntrar föräldern att följa barnets intresse och stanna upp, berätta eller ställa frågor till barnet, genererar oftast en längre lässtund jämfört med mer traditionell högläsning (De Temple \& Snow 2003).

Vally et al (2015) och Murray et al (2016) genomförde en studie i ett socioekonomiskt utsatt område där föräldrar coachades att läsa för sina barn enligt dialogläsningens metoder. Resultat visade på utveckling inom flera områden hos de barn som deltog $\mathrm{i}$ experimentgruppen. Barnens språk utvecklades mer jämfört med de barn vars föräldrar inte lärde sig dialogläsningsmetod (Vally et al 2015). Ett annat intressant resultat var att metoden även påverkade andra delar av barnens utvecklingsområden. De barn som deltog i studiens experimentgrupp utvecklade även sin koncentrationsförmåga, prosociala beteenden och sin förmåga att imitera. Även föräldrars beteenden påverkades till det positiva då resultat pekade på att de blev mer sensitiva och ömsesidiga gentemot sina barn. Studien genomfördes när barnen var 14-16 månader gamla. (Murray et al 2016).

\section{Utbildning av barnhälsovårdssjuksköterskor}

Dialogläsning är en viktig del av den kunskap som överförs till föräldrarna vid Språkstegens insatser. Redan för 25 år sedan pekade Svensson (1993) i sin doktorsavhandling ut det strategiskt så viktiga arbetet att genom information till föräldrar få möjlighet att påverka deras grad av interaktion med sina barn och även påverka kvaliteten på den stimulans som barnen får i hemmet.

Ett av de första stegen för att förbereda insatserna inom barnhälsovården blev att utbilda alla knappt 200 sjuksköterskor om läsning, läsfrämjande och varför läsning gynnar språkutvecklingen. Men hur skulle Språkstegen få sjuksköterskor som tidigare informerat om böcker och läsning att läsa tillsammans med barnet och föräldern, involvera, entusiasmera och på detta sätt metodiskt i varje familj visa hur dialogläsning går till samt stärka läsaridentiteten hos dem? 
Arbetsgruppen började med att modellera fram en utbildning genom ett pilotprojekt. Araby familjecenter och Växjö stadsbibliotek deltog i samarbetet och blev testobjekt för det upplägg som med modifiering sedan gavs åt i stort sett alla barnhälsovårdssjuksköterskor $\mathrm{i}$ båda länen (i Blekinge även psykologer och barnläkare). Under utbildningen fick deltagarna del av forskning och varför insatserna behövs i ett större samhällsperspektiv där språk har inflytande på t ex hälsa, jämlikhet, demokrati och utbildning. De fick kunskap om varför läsning är unikt för språkutveckling och att kvalitén på lässtunden är avgörande för outputen. Specifika ämnen som påverkar dialogläsningskontexten t ex flerspråkighet, familjer med läs- och skrivsvårigheter, analfabetism och genus togs också upp. Andra punkter var bibliotekskunskap och samtal om boken Knacka på (Tidholm).

En viktig ingrediens när man lär ut dialogläsning som metod är även att visa hur man gör och inte bara berätta vad man gör. Upplevelsen och erfarenheten av att bli läst tillsammans med är en viktig motivator som i Språkstegen ska finnas med vid insatserna vid både 8 och 18 månader. Därför var det nödvändigt att försöka förmedla detta även vid utbildning av personalen genom flera exempel på läsning ur småbarnsböcker. En positiv attityd till läsning i hemmet och föräldrarnas engagemang är avgörande för att öppna dörren till läsning hos barnet (Rydsjö 2012). Sjuksköterskornas egen inställning och grad av positiv attityd blir $\mathrm{i}$ någon mån därför en grind för familjen som i största möjligaste mån bör hållas öppen. Under eller i direkt anslutning till utbildningstillfället uppmuntrades till att prova att läsa enligt modellen med kollega eller annan person.

Vid utbildningarna har sjuksköterska, logoped, psykolog och biblioteksutvecklare medverkat för att belysa frågorna från olika akademiska fält och praktiker.

\section{Barnhälsovårdssjuksköterskorna som förmedlare - erfarenheter}

Efter ungefär sex månaders erfarenhet av Språkstegeninterventionen på 8-månadersbesök träffades pilotgruppen för att ge återkoppling och få tid för reflektion. Flera av sjuksköterskorna uttryckte under utbildningen en självklarhet hur man ville gå till väga, medan andra var försiktigt positiva men lite obekväma inför den nya praktiken att läsa, inte för ett eget barn eller barnbarn, utan i sin yrkesutövning. I pilotprojektet visade sig dessa hinder vara i stort sett övervunna när man fått in en vana. Distriktssköterskestudenterna Lavesson och Ramirez (2017) magisteruppsats Att underlätta tidig språkutveckling ger inblick i sju barnhälsovårdssjuksköterskors egen upplevelse av att arbeta med 8månadersinterventionen i Språkstegen. Här för författarna ett liknande resonemang efter att ha intervjuat deltagarna, "Några av deltagarna tycker att det känns lite ovant att komma hemma (sic.) till någon annan och 'ta över' med bokläsning för barnet. Deltagarna menar att ovanan förmodligen kommer att försvinna över tid med mer rutin." (Lavesson och Ramirez, s.22).

Vidare visade utvärderingen av piloten att vid nästan alla besök hade boken lästs tillsammans med barnet. Det fanns förstås också ganska ofta syskon som inkluderades. Pilotdeltagarna uppfattade att många föräldrar blev positivt överraskade och till och med förvånade över barnets reaktioner, interaktioner och samspel med läsaren. Även detta illustreras i Lavesson och Ramirez (2017) uppsats; "Föräldrarna blir i regel väldigt förvånade över att barnen lyssnar koncentrerat och deltar med sitt fokus". (Lavesson och Ramirez, s. 22-23). I piloten skedde läsningen ofta i början av besöket såvida inte barnet var upptaget 
med att sova eller äta och Språkstegendelen tog uppskattningsvis ca 15 minuter av hela besöket. Utbildningen som getts hade i stort sett motsvarat de behov som uppkommit i praktiken och man uppskattade särskilt att det fanns forskning att referera till och som grund för arbetet. Den största svårigheten uppfattades vara hembesök med tolk. Någon valde att inte involvera tolken i själva dialogläsningen utan endast när man talade om läsning. Vid tillfällen med telefontolk var det ännu svårare. Deltagarna berättade också att det anade att det såg mycket olika ut i vilken mån barnen tidigare blivit lästa för. Flera familjer hade inte några böcker alls i hemmet.

Så vitt det kan bedömas har sjuksköterskorna i breddinförandet ungefär samma upplevelser som i piloten.

I pilotprojektet fann personalen också att lässtunden och bokgåvan hade många positiva bieffekter. Att ge och få en gåva skapar en positiv känsla som stannar kvar under resten av besöket. Att det är barnhälsovården själva som kommer att bekosta Knacka på (Tidholm) kan förstärka denna känsla då det är sjuksköterskans egen organisation, ett vi, som ger boken till familjen. Några sjuksköterskor har också berättat om att boken och interaktionen under läsningen byggde nya relationella broar mellan barnet och den som läste med barnet. Några sjuksköterskor kunde i vissa fall under läsningen också se vissa beteenden hos barnet (tex imitation) som kunde bidra till att lättare observera barnets fortskridande utveckling. Dessa positiva bi-effekter har kanske medverkat till att Språkstegeninterventionerna inte genomförs eller upplevs som isolerade, utan är en del av hela besöket. Några i pilotstudien, men även i breddinförandet var så positiva till interventionen att de på eget initiativ systematiskt dialogläste andra boktitlar vid andra besök och åldrar. Detta om något visar hur medvetna, engagerade och positiva till metoden just dessa blev. Att få en hel kår i två län att förändra ett arbetssätt kan tyckas som en stor utmaning. Men kanske är sjuksköterskorna än mer motiverade än de som arbetar med planering och facilitering att bidra till förändring.

En utmaning sedan projektstart har varit att utbilda och inkludera nyanställda sjuksköterskor som behöver få samma goda förutsättningar som gruppen som varit med från början. För detta har genomförts uppsamlingsutbildning vid annan introduktionsutbildning samt avstämningar och möjlighet att ta upp frågor vid ordinarie grupphandledningar. Det har också tagits fram en skriftlig handledning för Språkstegeninterventionen vid 8- och 18 månader. Denna har alla sjuksköterskor fått. För många är den övertydlig och alltför strukturerad men säkerställer på ett bra sätt momenten vid interventionen och kan användas efter t ex en tjänstledighet eller vid introduktion av en efterträdare. Innehållet, kunskapen och attityden till läsning och dialogläsningsmodellen behöver också underhållas på andra sätt. Där sätts hopp till de lokala Språkstegennätverken där barnbibliotekspersonalen kan förmedla kunskap och inspiration. Gemensamma konferenser kan också fylla detta behov.

Vi har i denna framställning visat på forskningsstödet för, kontexten till dialogläsning som metod och praktiken av den metoden i just Språkstegen. Dialogläsning som metod $\mathrm{i}$ insatserna vid 8 och 18 månader i barnhälsovårdens program i Blekinge och Kronoberg bör dock inte ses isolerat. När utvecklingsarbetet Språkstegen etablerats hoppas vi kunna se att de sammantagna insatserna har ökat föräldrarnas medvetenhet, motivation, positiva inställning och kunskap. Men framför allt önskar vi att deras frekvens av läsning och kvaliteten i samspelet under läsningen med barnen har ökat. 


\section{Sammanfattning}

Att små barn växer upp i en språkligt stimulerande miljö är av vikt för deras utveckling. Föräldrar har olika kunskap, förmågor och möjlighet att erbjuda sina barn denna stimulans, något som skapar ojämlika uppväxtvillkor (Hart och Risley 1995). Barnhälsovården har som uppgift att möta familjer, erbjuda föräldrar verktyg för att barnen skall få bästa möjliga miljö att växa och utvecklas i (Rikshandboken Barnhälsovård). Att införa språkfrämjande insatser, som exempelvis Språkstegen som helhet och dialogläsning specifikt, kan ses som en insats för att minimera barns olika uppväxtvillkor vad gäller språkmiljö. Att få information, se metoden utövas med sitt barn och få insikter i dialogläsningens tekniker av en person som familjen redan har en relation till (barnhälsovårdssjuksköterska) skapar goda förutsättningar för att föräldern själv ska kunna erbjuda regelbunden språkstimulans till sitt barn. Tidigare studier av Vally et al (2015) och Murray (2016) pekar på att dialogläsning som metod gynnar både föräldrar och barn på många sätt, inte enbart barnets språkutveckling. Vilka ytterligare effekter som dialogläsningens metoder kan ge barn och föräldrar när de implementeras tidigt i barnets liv är av intresse och kommer framöver att belysas i de studier som planeras i kommande doktorsavhandling av Emma Bergström.

Språkstegens styrka är att under de första åren i barnets liv återkommande erbjuda kunskap, stöd och insatser enskilt och i grupp. Dessa insatser är möjliga på grund av det övergripande samarbete som inletts mellan barnhälsovård, regionbibliotek, folkbibliotek och representanter för logopedi samt de nationella projektmedel Språkstegen fått genom Kulturrådets satsning Bokstart. 


\section{Litteraturförteckning}

Bartl-Pokorny, Katrin D., Marschik, Peter B., Sachse, Steffi, Green, Vanessa A., Zhang, Dajie, van der Meer, Larah, Wolin, Thomas \& Einspieler, Christa (2013). "Tracking Development From Early Speech-Language Acquisition to Reading Skills at Age 13". Developmental Neurorehabilitation, Vol. 16(3), s. 188-195.

Broberg, Anders, Granqvist, Pehr, Ivarsson, Tord \& Risholm Mothander, Pia (2017). Anknytningsteori: Betydelsen av nära känslomässiga relationer. Natur och Kultur.

Bus, Adriana G. \& Van IJzendoorn, Marinus H. (1988). “Mother-Child Interactions, Attachment, and Emergent Literacy: A Cross-sectional Study". Child Development, Vol. 59 (5), s. 1262-1272.

Bus, Adriana G. \& Van IJzendoorn, Marinus H. (1995). "Mothers Reading to their 3-year-olds: the Role of Mother-Child Attachment Security in Becoming Literate". Reading Research Quarterly, Vol. 30 (4), s. 998-1015.

Bus, Adriana G., Van IJzendoorn, Marinus H. \& Pellegrini, Anthony D. (1995). “Joint Book Reading Makes for Success in Learning to Read: A Meta-Analysis on Intergenerational Transmission of Literacy". Review of Educational Research, Vol 65(1), s. 1-21.

DeBaryshe, Barbara D. (1993). "Joint Picture-Book Reading Correlates of Early Oral Language skill”. Journal of Child Language, Vol. 20 (2). s.455-461.

De Temple, Jeanne \& Snow, Catherine E. (2003). "Learning Words From Books". On Reading Books to Children. Parents and Teachers. Red. Anne van Kleeck, Steven A. Stahl \& Eurydice B. Bauer. Mahwah, New Jersey: Lawrence Erlbaum Associates, Publishers, s. 16-36.

Dickinson, David K., Griffith, Julie A., Michnick Golinkoff, Roberta \& Hirsh-Pasek, Kathy (2012). "How Reading Books Fosters Language Development around the World". Child Developmental Research, Vol 2012, s. 1-15.

Duursma, Egbert, Augustyn, Marilyn \& Zuckerman, Barry (2008). "Reading Aloud to Children: the evidence". Archives of Disease in Childhood, Vol. 93 (7), s. 554-557.

Fletcher, Kathryn L. \& Reese, Elaine (2005). “Picture Book Reading With Young Children: A Conceptual Framework". Developmental Review, Vol. 25, s. 64-103.

Hart, Betty \& Risley, Todd R. (1995). Meaningful differences in the everyday experience of young American children. Baltimore: Brookes Publishing.

Isbell, Rebecca, Sobol, Joseph, Lindauer, Liane \& Lowrance, April (2004). "The Effects of Storytelling and Story Reading on the Oral Language Complexity and Story Comprehension of Young Children". Early Childhood Education Journal, Vol. 32 (3), s.157-163. 
Karlsson, Kay (2012). Anknytning: Om att tolka samspelet mellan föräldrar och små barn. Stockholm: Gothia Fortbildning.

Karrass, Jan. VanDeventer, Meghan C. \& Braungart-Rieker, Julia M. (2003). "Predicting Shared Parent-Child Book Reading in Infancy". Journal of Family Psychology, Vol. 17 (1), s. 134-146.

Lavesson, Glenda \& Ramirez, Nathalie (2017). Att underlätta tidig språkutveckling: Barnhälsovårdssjuksköterskans erfarenhet av att delta i Språkstegen vid åttamånadersbesöket - en intervjustudie. Blekinge tekniska högskola.

Lyytinen, Paula, Laakso, Marja-Leena, Poikkeus, Anna-Maija (1998). "Parental Contribution to Child's Early Language and Interest in Books". European Journal of Psychology of Education, Vol. XIII (3), s. 297-308.

Mol, Suzanne E., Bus, Adriana G., de Jong, Maria T. \& Smeets, Daisy J.H. (2008). “Added Value of Dialogic Parent-Child Book Readings: A Meta-Analysis". Early Education and Development, Vol. 19(1), s. 7-26.

Mol, Suzanne E. \& Bus, Adriana G. (2011). "To Read or Not to Read: A Meta-Analysis of Print Exposure From Infancy to Early Adulthood". Psychological Bulletin, Vol. 137(2), s. 267-296).

Montag, Jessica L., Jones, Michael N. \& Smith, Linda B. (2015). "The Words Children Hear: Picture Books and the Statistics for Language Learning". Psychological Science, Vol. 26 (9), s. 1489-1496.

Murray, Lynne, De Pascalis, Leonardo, Tomlinson, Mark, Vally, Zahir, Dadomo, Harold, MacLachlan, Brenda, Woodward, Charlotte \& Cooper, Peter J. (2016). "Randomized Controlled Trial of a Book-Sharing Intervention in a Deprived South African Community: Effects on Carer-Infant Interactions, and their Relation to infant Cognitive and Socioemotional Outcome". Journal of Child Psychology and Psychiatry, Vol. 57 (12), s. 13701379.

Region Kronoberg (2014). Länsgemensam handlingsplan - strategi för barns och ungas uppväxtvillkor 2015-2018. Hämtad 29 augusti 2018, från https://www.vaxjo.se/download/18.59777ce315d3abb235132a09/1500379496765/L\%C3\% A4nsgemensam\%20strategi\%20barns\%20och\%20ungas\%20uppv\%C3\%A4xtvillkor\%20 1509 22.pdf

Region Uppsala. Sektorsövergripande samarbete/samverkan kring de yngsta barnens språkoch läsutveckling i Uppsala län Språknätet. Hämtad 28 augusti 2018, från http://www.lul.se/Kultur/Regionbibliotek-Uppsala/Spraknatet1/

Rikshandboken Barnhälsovård. Barnhälsovårdens nationella program. Hämtad 29 augusti 2018, från https://www.rikshandboken-bhv.se/metoder--riktlinjer/barnhalsovardensnationella-program/ 
Rydsjö, Kerstin (2012). Dags att höja ribban!? En rapport om samverkan mellan barnhälsovård och bibliotek kring små barns språk- och litteracitetsutveckling. Region Halland.

SFS 2013:801. Bibliotekslag. Stockholm: Kulturdepartementet.

Shahaeian, Ameneh, Wang, Cen, Tucker-Drob, Elliot, Geiger, Vincent, Bus, Adriana G., \& Harrison, Linda J (2018). "Early Shared Reading, Socioeconomic Status, and Children's Cognitive and School Competencies: Six Years of Longitudinal Evidence" Scientific Studies of Reading, s. 1-18.

Språkstegen. Om Språkstegen. Hämtad 30 augusti 2018, från http://www.sprakstegen.se/om-sprakstegen/sprakstegen-blekinge-kronoberg/

Statens Kulturråd (2014). Handlingsprogram för läsfrämjande. Hämtad 29 augusti 2018, från http://www.kulturradet.se/Documents/L\%C3\%A4sfr\%C3\%A4mjande/handlingsprogram lasf ramjande.pdf

Svensson, Ann-Katrin (1989). BokNallen: Utvärdering av ett språkstimuleringsprojekt. Malmö: Lärarhögskolan, Institutionen för pedagogik och specialmetodik. Svensson, Ann-Katrin (1993) Tidig språkstimulering av barn. Lunds universitet.

von Tetzchner, Stephen (2016). Utvecklingspsykologi. Lund: Studentlitteratur.

Tidholm, Anna-Clara (1992). Knacka på. Stockholm: Alfabeta Bokförlag AB.

Vally, Zahir, Murray, Lynne, Tomlinson, Mark \& Cooper, Peter J. (2015). "The Impact of Dialogic Book-Sharing Training on Infant Language and Attention: a Randomized Controlled Trial in a Deprived South African Community". Journal of Child Psychology and Psychiatry, Vol. 56 (8), s. 865-873.

Walker, D., Greenwood, C., Hart, B. \& Carta, J. (1994) Prediction of School Outcomes Based on Early Language Production and Socioeconomic Factors. Child Development, 65, 606-621.

Wallby, Thomas (2012). "Lika för alla? Social position och etnicitet som determinanter för amning, föräldrars rökvanor och kontakter med BVC". Uppsala Universitet.

Westerlund, Monica (2009). Barn i början. Språkutveckling i förskoleåldern. Stockholm: Natur och Kultur.

Whitehurst, G.J., Falco, F.L., Lonigan, C.J., Fischel, J.E., DeBaryshe, B. D., Valdez-Menchaca, M.C., \& Caulfield, M. (1988). "Accelerating Language Development Through Picture Book Reading". Developmental Psychology Vol 24(4), s. 552-559.

Zevenbergen, Andrea \& Whitehurst, Grover (2003). “Dialogic Reading: a Shared Picture Book Reading Intervention for Preschoolers". On Reading Books to Children: Parents and Teachers. Red. Van Kleeck, A, Stahl, SA, Bauer, EB. Mahwah, NJ: Lawrence Erlbaum, s. 177-200. 
Ögland, Malin (2013). Taxonomier - verktyg för verksamhetsutveckling. Regionbibliotek Stockholm. 